\title{
Imagem e devoção em tempos de pandemia: apontamentos sobre a Peste Negra e a religio- sidade cristã no fim da Idade Média
}

\section{Tamara Quírico1}

Resumo: Tendo como pano de fundo a atual pandemia de Covid-19, queremos discutir no presente artigo a produção artística que se desenvolve no fim da Idade Média na Europa, particularmente após o surto de Peste Negra. O objetivo é lançar nova luz sobre essa arte, tirando-a de um esquecimento oriundo de um preconceito ultrapassado, porém ainda presente nos nossos dias.

Palavras-chave: Peste Negra, religiosidade cristã, arte cristã, devoção.

\section{Image and devotion in pandemic times: notes on the Black Death and Chris- tian religiosity by the end of the Middle Ages}

\begin{abstract}
As the Covid-19 pandemic spreads, we shall discuss in this paper the art developed by the end of the Middle Ages in Europe, particularly after the Black Death. We want to shed new light onto this art, as we aim to surpass an out-to-date, but still present, prejudice regarding it.
\end{abstract}

Keywords: Black Death, Christian religiosity, Christian art, devotion.

1 É professora Adjunta do Instituto de Artes da UERJ. Dedica-se especialmente a pesquisas sobre a pintura italiana entre os séculos XIII e XV. É autora de diversos estudos relacionados a usos e funções das imagens cristãs e práticas devocionais ligadas a essas imagens. Dentre suas publicações, destaca-se o livro Inferno e Paradiso. As representações do Juízo Final na pintura toscana do século XIV (Editora da Unicamp, 2014). É membro do Comitê Brasileiro de História da Arte (CBHA). Vínculo institucional: Universidade do Estado do Rio de Janeiro, São Francisco Xavier, 524 - Maracanã, Rio de Janeiro, R.J, 20943000. E-mail: tamara. quirico@uerj.br. ORCID: https://orcid.org/0000-0003-0024-4737. Lattes iD: http://lattes.cnpq.br/2136677343472870. Rio de Janeiro, Brasil. 
Vivemos hoje, possivelmente, um momento assustadoramente definidor da existência humana. Um tempo que será recordado no futuro: a época em que o mundo parou em função de uma doença que, de forma veloz e inesperada, se disseminou, causando medo, criando ausências e expectativas.

Poucos são os eventos (seja de ordem natural ou não) que, ao longo da História, realmente impactaram o homem em escala global. Em um passado mais recente, temos a Segunda Guerra Mundial, é claro. Retrocedendo no tempo, com bastante frequência se menciona também, no mesmo sentido, a Peste Negra (ainda que em uma escala mais reduzida, tendo em vista que nesse caso estamos discutindo não somente o mundo até então conhecido, como mais especificamente ainda a Europa e a Ásia). São diversas as relações possíveis entre o que ocorreu em meados do século XIV e o que vivenciamos hoje, fazendo com que muitos busquem eventuais similaridades nas consequências que o surto trouxe no fim da Idade Média, e o que poderá acontecer na contemporaneidade. Ainda é cedo demais para podermos avaliar os desdobramentos da epidemia de Covid-19, seja para as sociedades, de modo geral, seja para a arte contemporânea. Infelizmente, porém, o resultado dessas aproximações que vêm sendo feitas na atualidade são falsas analogias e interpretações equivocadas do que ocorreu no século XIV. Para corrigir esses enganos, e discutir de forma séria questões relacionadas à produção artística na Europa na segunda metade do Trecento, trataremos da epidemia de peste e suas consequências.

O surto de Peste Negra, a partir de 1347, devastou parte do mundo então conhecido. Os testemunhos de época atribuem sua origem à Ásia central, "onde ela existia em estado endêmico" ${ }^{1}$. Na Europa, a epidemia teria chegado com os navios genoveses vindos do Oriente; a doença se alastraria após esses navios aportarem na cidade de Pisa, na Península Itálica, conforme crônicas de época².

O geógrafo canadense Harold D. Foster (1943-2009) estimou que esse primeiro grande surto de peste foi provavelmente o segundo maior de-

1 Wolff, 1988, p. 15.

2 "Negli anni 1348, alla entrata di gennaio, venne a Pisa due ghalee di Genovesi le quali vennono di Romania, et chome furono gunti alla piaza del pesce, qualunque persona favellò a quelli delle decte due ghalee di subito si era amalato et morto (...)" ["Em 1348, no início de janeiro, chegaram a Pisa duas galeras de genoveses que vieram da Romênia, e como chegaram à praça do peixe, qualquer pessoa [que] falou com aqueles das ditas duas galeras imediatamente adoeceu e morreu (...)"]. Sardo, 1963, p. 96. 
sastre na história do homem; ele ficaria atrás somente da Segunda Guerra Mundial, já no século XX. Isto porque, de acordo com suas concepções, os desastres deveriam ser medidos não apenas pelo número de vítimas fatais que causaram, mas também pelos danos físicos e emocionais que acarreta$\mathrm{ram}^{3}$. Ainda que critiquemos suas escolhas metodológicas, tendo em vista que busca quantificar emoções - tarefa assaz difícil de ser empreendida, uma vez que sentimentos são, por definição, subjetivos, e especialmente quando se trata de um acontecimento tão distante no tempo -, não há dúvidas de que a Peste Negra foi um dos piores desastres já registrados pelo homem ${ }^{4}$.

A discussão que queremos propor no presente artigo diz respeito às consequências que um evento desse porte, tão definidor dos rumos da humanidade, poderia ter também sobre a produção artística imediatamente posterior. Houve, efetivamente, consequências? Houve mudanças na arte produzida na segunda metade do século XIV?

É ponto básico já assumido pela historiografia o fato de que a Peste Negra foi um grande divisor de águas para as sociedades europeias, e que parece efetivamente ter gerado mudanças significativas nos modos de vida, na economia e, de particular importância para nossa presente discussão, nas mentalidades religiosas. As muitas implicações da epidemia podem ser percebidas ao menos até as primeiras décadas do século $\mathrm{XV}$, e mesmo posteriormente.

A primeira grande consequência que percebemos acerca da Peste Negra é o aumento expressivo nas taxas de mortalidade nas regiões mais afetadas, justamente durante os meses de verão - época mais propícia para a proliferação da doença, embora ela se manifestasse também em outras épocas do ano, como a crônica de Ranieri Sardo nos indica ${ }^{5}$. Se as taxas

3 A pesquisa de Foster é citada e comentada por Lerner, 1985, p. 533.

4 Fazendo uma vez mais um paralelo com a história recente, escreve o historiador da arte italiano Lorenzo Lorenzi, comentando as consequências da epidemia sobre Florença, que "tal desastre possui comparação com a idade contemporânea somente com os efeitos da [bomba] atômica sobre Hiroshima e Nagasaki". Lorenzi, 1996, p. 141. Não pretendemos nos aprofundar nas discussões sobre as origens da Peste Negra e sua difusão na Europa, assim como suas consequências sobre as mentalidades. Há dezenas de trabalhos que já trataram do tema. Gostaríamos de mencionar uma contribuição em português, que traz uma extensa bibliografia sobre o assunto: Quírico, 2012. E, especificamente sobre o contexto português, Bastos, 2009.

5 Ver nota 2, acima. Sobre as taxas de mortalidade, podemos mencionar o registro paroquial de 
populacionais já vinham em declínio na Europa desde o início do século XIV - pensemos nas guerras e na carestia de alimentos que se seguiu a um período de mudanças climáticas que afetaram intensamente a agricultura europeia na primeira metade do século -, não há dúvidas de que o surto acelerou o processo.

A mortalidade foi significativamente diferente conforme a cidade ou a região, em uma proporção que variou entre um oitavo e dois terços da população ${ }^{6}$. O que desejamos destacar, nesse ponto, é exatamente essa discrepância nos números: se houve cidades praticamente dizimadas pela peste ${ }^{7}$, outras, muitas vezes próximas, foram poupadas. Foi o que ocorreu com Milão em 1348. Esses números tão distintos reforçaram a interpretação, na época, de que a Peste Negra teria sido um castigo de Deus pelas iniquidades do homem, conforme um topos tradicional já estabelecido pela tradição bíblica veterotestamentária desde a narrativa sobre as pragas do Egito. Essa compreensão do surto como punição divina fez com que muitos buscassem meios de expiação de seus pecados, seja através de mortificações da carne, seja através de doações para instituições religiosas.

O ano de 1348 foi, portanto, determinante para os rumos da história europeia. Devemos ponderar, por outro lado, o fato de sabermos hoje que os surtos recorrentes de peste ao longo dos séculos XIV e XV - menos impactantes e dramáticos quando pensamos em taxas de mortalidade, todavia frequentes - se mostraram mais influentes em relação às mudan-

Givry, na Borgonha, no século XIV. Aqui, constatam-se trinta e nove falecimentos em 1345, vinte e cinco em 1346, quarenta e dois em 1347. Em 1348, no entanto, o número de óbitos saltou para 649 - sendo que 615 somente no período entre dois de agosto e dezenove de novembro. Cf. Wolff, 1988, p. 21. Destaquemos ainda outro ponto: o historiador Michael Goodich (1944-2006) afirma que, entre os anos 1250 e 1360, o número de filhos por família diminuiu drasticamente em algumas regiões europeias, de 3,5 para 1,9. Cf. Goodich, 1995, p. 86. Por fim, o cronista Ranieri Sardo, que escreveu sobre Pisa entre 1354 e 1399, estimou que de cada cinco habitantes, quatro teriam morrido durante os cinco meses da primeira peste: "Et questa pistolenza durò insino al maggio (...); morirono de' cincque e' quattro, et sicchome fu in Pisa, chosi fu per tucto l'altro mondo et u' più e u' meno, et di questo fu qui il principio" ["E esta pestilência durou até maio (...); morreram de [cada] cinco, quatro, e assim como foi em Pisa, assim foi por todo o outro mundo e em alguns [lugares] mais e em alguns menos, e disso foi aqui o princípio"]. Sardo, 1963, p. 96.

6 Cf. Wolff, 1988, p. 20.

7 Para algumas cidades toscanas, como Siena, Volterra e San Gimignano, William Bowsky (19302013) afirma que apenas no século XX a população conseguiu, enfim, retornar aos números populacionais de antes da peste. Cf. Bowsky, 1964, p. 09. Enrico Fiumi (1908-1976) mostra que em 1950 "a população de San Gimignano está ainda abaixo das cifras do período comunal". De fato, a cidade contava apenas com 11.062 habitantes nessa data, contra os 13.000 estimados em 1339. Em 1350 - data precisada pelo livro de bocas das terras e das vilas - a população de San Gimignano havia se reduzido a apenas 3997. Fiumi, 1961, p. 174. 
ças nas mentalidades religiosas do período ${ }^{8}$. Surtos menos intensos, mas que teriam sido como novas ondas vindas sobre alguém que havia apenas conseguido retomar o fôlego após quase se afogar no mar, e que teriam reforçado, desse modo, os sentimentos de desesperança e de abandono trazidos pelo primeiro grande surto.

Passemos, enfim, à arte. Estudando especificamente a Peste Negra e seus desdobramentos no campo artístico, não há como não tratarmos de Painting in Florence and Siena after the Black Death, livro publicado pelo historiador da arte norte-americano Millard Meiss (1904-1975) em 1951, e que se tornou, com o passar do tempo, um dos grandes clássicos da História da Arte, inescapável especialmente, mas não somente, para os pesquisadores que se debruçam sobre a arte de fins do Medievo.

Essa questão já foi tratada anteriormente ${ }^{9}$, mas, dadas as repercussões na atualidade por conta da pandemia de Covid-19, vale ser retomada aqui. Partindo do pressuposto do impacto da epidemia sobre as sociedades europeias, Meiss defende a tese de que a Peste Negra afetou profundamente as cidades de Siena e Florença, bastante atingidas pela primeira onda da epidemia, assim como boa parte da região da Toscana, na Península Itálica. Conforme o historiador da arte, esse primeiro grande surto teria gerado também mudanças nas concepções artísticas do período, tendo em vista transformações nas sensibilidades culturais e religiosas que teriam ocorrido após o evento.

Analisando algumas obras específicas produzidas na segunda metade do século XIV, Meiss teria percebido um abandono das inovações trazidas por Giotto di Bondone (ca.1265-1337) à arte toscana, retornando a um esquema compositivo mais "primitivo", mais de acordo com os padrões do século XIII. Abandono, ainda segundo Meiss, gerado pelo clima de pessimismo e medo que se instalara após o surto. Analisando o chamado $R e-$ tábulo do Redentor, pintado por Andrea Orcagna (ca.1308-1368) e ainda

8 Sabemos que a peste, na verdade, continuou se manifestando de forma esporádica e recorrente até o século XVIII. Na Península Itálica, após a primeira grande epidemia em 1348, houve surtos periódicos em 1358, 1362, 1363, 1366, no início da década de 1370, 1373, 1383, 1384, 1400, $1439,1451,1452,1458,1476,1494,1622$ e 1743, quando parece ter desaparecido, finalmente, na cidade de Messina. Cf. Cohn, Jr, 2002, p. 72 a 77.

9 Quírico, 2015b. 
Figura 1

Andrea Orcagna

Redentor que

apresenta as

chaves a São

Pedro e um livro

a Santo Tomás

de Aquino, com a

Virgem, São João

Batista, São Jorge,

Santa Catarina

de Alexandria

São Paulo e São

Lourenço (Retá-

bulo do Redentor),

ca.1354-1357

Têmpera e ouro

sobre madeira

$296 \times 160 \mathrm{~cm}$

Florença, Capela

Strozzi, Igreja

de Santa Maria

Novella

Disponível em:

<https://com-

mons.wikime-

dia.org/wiki/

File:8_Andrea

di_Cione_Orcag-

na,_Strozzi_Altarpiece._1354-57,

Santa_Maria_No-

vella,_Florence..

jpeg>. Acesso

em 16 de abril de

2020

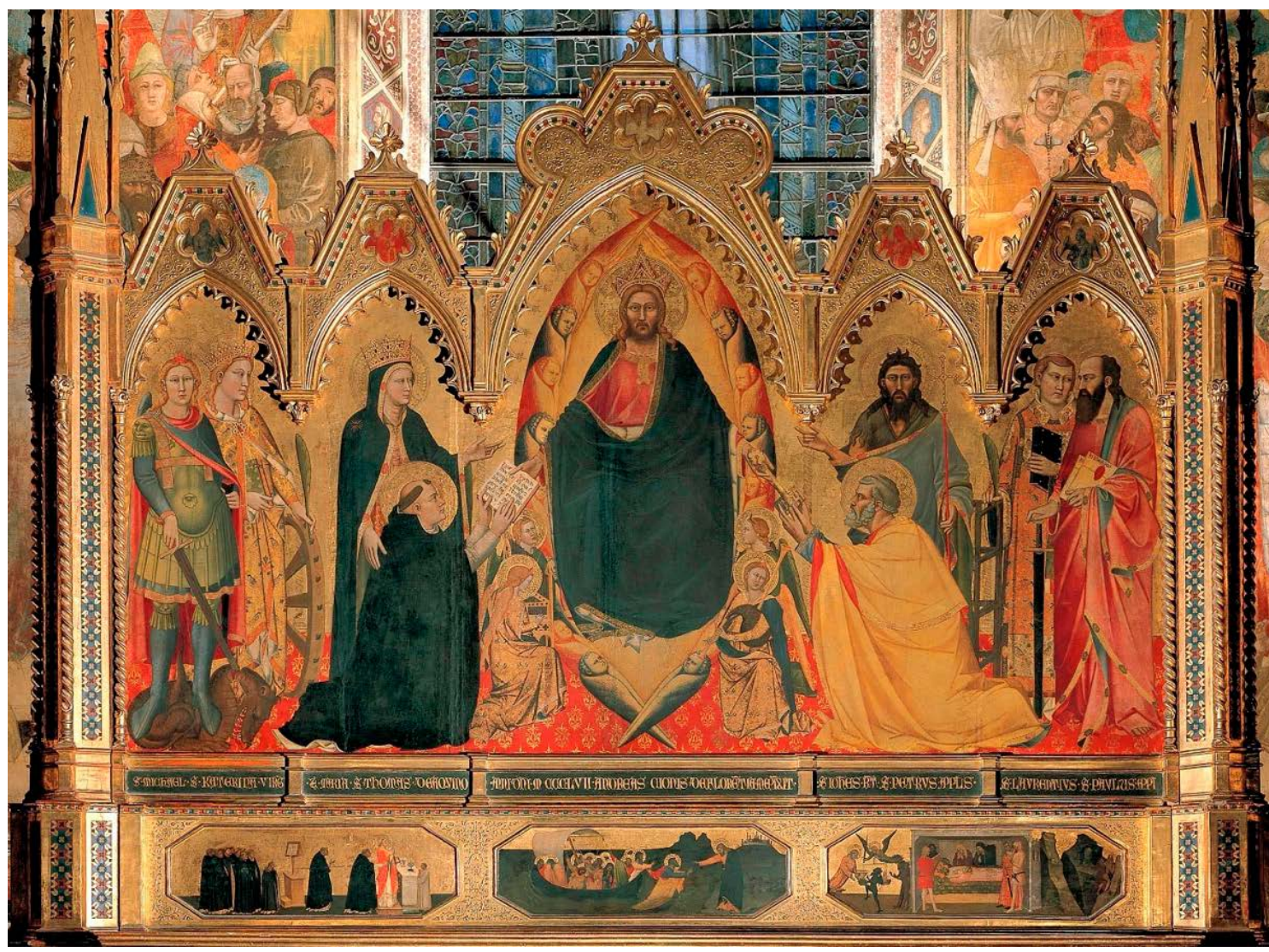

hoje em seu posicionamento original, sobre o altar da Capela Strozzi, na Igreja de Santa Maria Novella, em Florença [Figura 1], afirma ele que

A representação na última parte do século XIV de temas como o da Trindade e do Cristo em Majestade em vez do da Madonna com o Menino surge da intenção de magnificar o reino do divino enquanto se reduz o do humano. Uma intenção semeIhante é evidente (...) na pintura da história sagrada, que acentua o milagroso no lugar do natural, o misterioso em vez do familiar e humano. ${ }^{10}$

Como a peste foi interpretada como castigo divino, segundo Meiss, seria desejável que os homens abandonassem o materialismo do mundo, e buscassem um contato mais próximo com Deus. De acordo com suas concepções, após um evento tão traumático e marcante, que influenciou profundamente a humanidade, seria conveniente que houvesse também uma renúncia ao humanismo trazido à arte por Giotto e seus seguidores, que 
tivera como consequência o desenvolvimento de uma linguagem mais naturalista, com maior volumetria, espacialidade e pathos [Figura 2]. Segundo Meiss, nada disso seria considerado relevante após 1348; a arte deveria, outrossim, buscar uma ênfase maior no espiritual, desprezando o mundo natural, buscando o perdão de Deus ${ }^{11}$. Segundo ele, é o que teria ocorrido na arte toscana na segunda metade do século XIV.

Figura 2

Giotto di Bondone

Fuga para o Egito,

ca.1305

Afresco, $200 \times 185$

cm. Pádua, Capela

Scrovegni

Disponível em: $<$ https://commons.wikimedia.org/wiki/ File:Giotto_di_ Bondone_No._20_Scenes from_the_Life_ of_Christ_-_4.

Flight_into_

Egypt_-WGA09198.jpg> Acesso em 04 de setembro de 2020

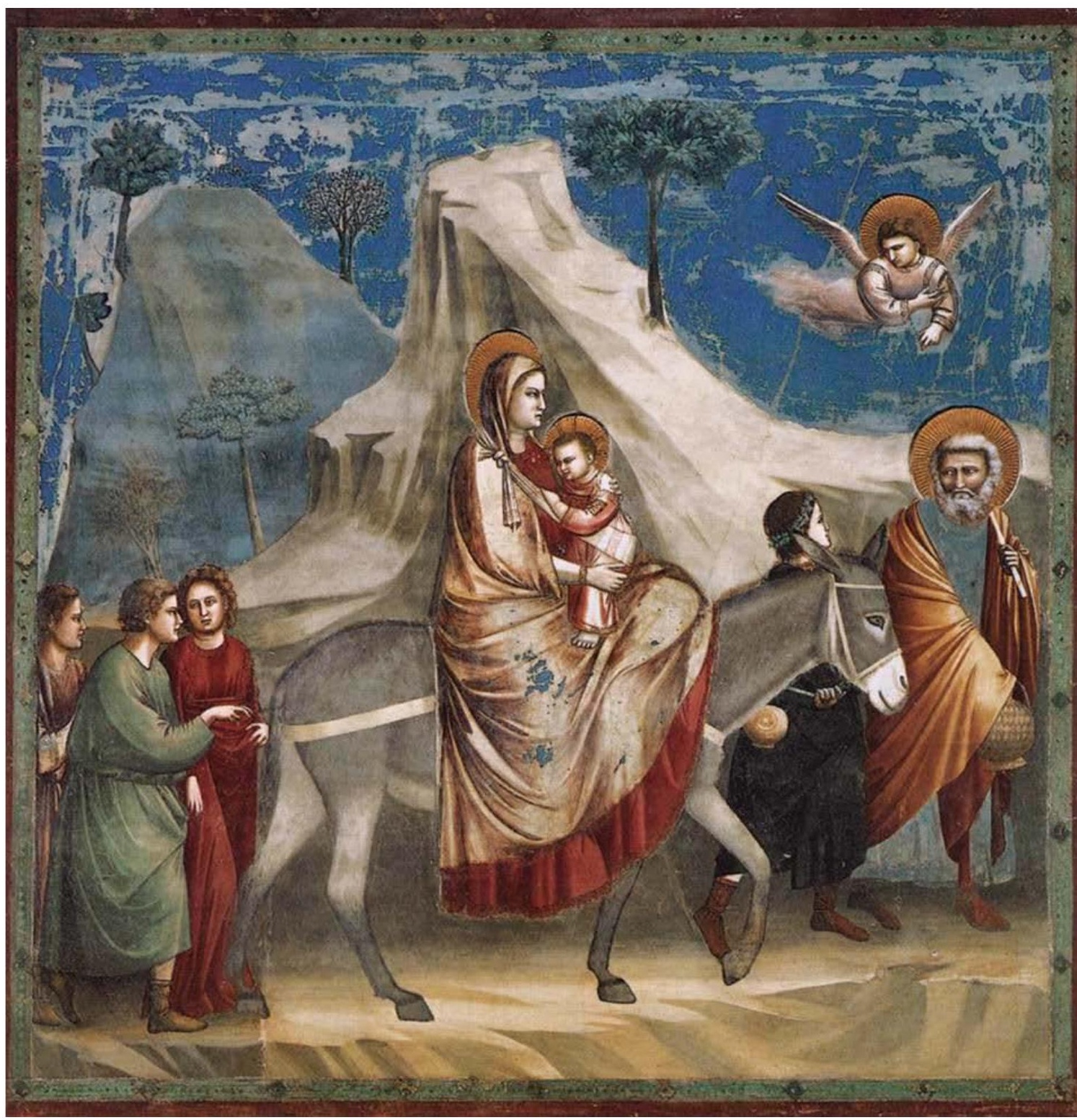

11 Meiss também analisa em seu livro temas específicos, como o da Madonna da Humildade, e a figuração do Cristo Juiz em cenas do Juízo Final. Não nos deteremos nessa discussão. Sobre as representações do Juízo Final e do Cristo Juiz, ver Quírico, 2014, e Quírico, 2013. 
A partir dessas questões levantadas por Millard Meiss, devemos enfatizar um ponto essencial para melhor compreendermos suas análises: ainda que de modo inconsciente, o historiador da arte assumiu um posicionamento acerca da arte da segunda metade do século XIV que remete, evidentemente, às ideias de Jacob Burckhardt (1818-1897) sobre a cultura do Renascimento, ou seja, de que os séculos XV e XVI representariam a fundação da modernidade ${ }^{12}$, rompendo finalmente com um obscurantismo que teria marcado os mil anos que separaram o fim da Antiguidade Clássica do século $X V$, período definido, por conta disso, pela negativa alcunha de “idade das trevas". Se em 1860, ou mesmo em 1951, seria ainda aceitável (mesmo que incorreto) assumir essa posição, que se relaciona, em última instância, às concepções culturais e artísticas do século XVI, atualmente não poderíamos mais corroborar essa análise simplista, redutora e equivocada, seja da Idade Média ${ }^{13}$ como um todo, seja, em particular, de seu período final ${ }^{14}$. Como escreve a historiadora da arte norte-americana Judith Steinhoff, comentando a atual disseminação da Covid-19, "termos uma compreensão mais imediata e pessoal dos horrores trazidos por uma pandemia não dará credibilidade renovada à teoria de Meiss sobre a arte pós-Peste Negra"15.

Ou, ao menos, não deveria dar nova credibilidade. Infelizmente, não é o que acontece. Essa concepção parece ainda vigorar nos dias de hoje, re-

12 "Os contornos espirituais de uma época cultural oferecem, talvez, a cada observador uma imagem diferente, e, em se tratando do conjunto de uma civilização que é a mãe da nossa e que sobre esta ainda hoje segue exercendo sua influência, é mister que juízo subjetivo e sentimento interfiram a todo momento tanto na escrita como na leitura desta obra" (grifo nosso). Burckhardt, 2009, p. 36. Sobre Burckhardt, escreve Jacques Le Goff que "é ele que inventa o Renascimento, com $\mathrm{R}$ maiúsculo, isola-o da Idade Média e estabelece esse corte definitivo. Burckhardt joga com a antítese. Opõe esse período - o Renascimento - ao tempo das trevas, que ainda não estava claramente circunscrito, nem datado. Sua Civilização do Renascimento na Itália (1860), de resto um grande livro, cria um corte decisivo". Le Goff, 2008, p. 60.

13 O termo Idade Média é empregado aqui, decerto, de forma bastante ampla. Devemos ter consciência de que o período de cerca mil anos abarcado por ele foi caracterizado por sociedades e culturas bastante diversas, e que produziram igualmente objetos artísticos singulares que não caberiam, a priori, em uma única conceituação teórica.

14 Lionello Venturi (1885-1961) comenta que "enquanto em poucos anos de academia de belas-artes se puder aprender a reproduzir os escorços e os emaranhados anatômicos melhor do que os grandes mestres primitivos, e se acreditar que esse aprendizado constitua a base da arte, enquanto o amor aos primitivos estiver atrelado a um senso de generosa, satisfeita, na verdade divertida indulgência pela inabilidade das crianças, enquanto se opuser a 'religiosidade' dos trecentistas à 'arte' dos quinhentistas, até então o preconceito da imitação da natureza reinará soberano, e os primitivos continuarão a ser para nós letra morta". Venturi, 1972, p. 05. "Primitivo" aqui, é claro, não possui qualquer conotação negativa.

15 Steinhoff, 2020, p. 23. 
forçada através de indagações diversas sobre as possíveis consequências da pandemia de Covid-19: ou seja, a noção a de que o período posterior à Peste Negra, e sua produção artística (particularmente importante para nosso argumento), teriam representado um retrocesso, em uma conotação decerto negativa dessa arte ${ }^{16}$. "Retrocesso", como já destacamos, em relação à grandiosidade do que havia sido criado na primeira metade do Trecento por Giotto e seus seguidores, especialmente por Bernardo Daddi (ca.1290-ca.1348), Taddeo Gaddi (ca.1290-1366) e Maso di Banco (ativo a partir de 1320-ca.1348). Os três pintores, de fato, foram bastante atuantes no ateliê florentino de Giotto, mas alcançaram também notoriedade própria, tendo sido responsáveis pela execução de alguns dos mais importantes ciclos de pintura realizados em Florença em meados do século XIV. Taddeo morre somente em 1366; Bernardo, e talvez também Maso, ironicamente, parecem ter morrido durante o surto de peste em 1348, assim como diversos outros artistas (por exemplo, os irmãos sienenses Pietro e Ambrogio Lorenzetti, nascidos, respectivamente, em ca.1280 e ca.1290), o que reforçaria a noção de um retrocesso na arte devido a um vazio repentino de talentos, à ausência súbita de mestres que pudessem servir de modelo para as novas gerações.

Predomina, desse modo, ainda hoje a noção de que a segunda metade do século XIV foi marcada por uma interrupção no desenvolvimento das artes visuais em direção a um progressivo naturalismo. Teria havido entre a primeira metade do Trecento e o Quattrocento um hiato equivalente, ainda que em uma escala evidentemente menor, ao que ocorreu entre a Antiguidade Clássica e o Renascimento; assim, o período pós-Peste Negra teria sido uma época deficiente e, por conseguinte, menos relevante, em termos artísticos. Conforme escreve Steinhoff, "a mais difundida concepção da primeira metade do século [XIV] é a de que foi um período caracterizado por mudança e invenção. A arte da segunda metade do Trecento é geralmente ou polidamente ignorada ou definida como imitações inferiores dos monumentos do período anterior"17.

16 Sobre a persistência desse tipo de visão negativa na contemporaneidade, ver, por exemplo, o artigo "Bubonic plague in Europe changed art history. Why coronavirus could do the same", publicado no Los Angeles Times no fim de março de 2020: "Ele [Giotto] preparou [o caminho] para uma revolução na pintura na segunda metade do século XIV. Mas ela nunca chegou”. Knight, 2020.

17 Steinhoff, 2014, p. 07. Sobre as aproximações que podem - devem - ser feitas entre a produção artística do século XIV e a do século XV, ver Quírico, 2017, e Quírico, 2018. 
Não negamos que tenha havido mudanças na arte na segunda metade do século XIV. Por exemplo, se a Peste Negra não foi a responsável pelo desenvolvimento de temas macabros na arte - cenas do Encontro dos três vivos com os três mortos, assim como do Triunfo da Morte, surgem tanto na literatura como nas artes visuais ainda no século XIII ${ }^{18}$ - é fato que eles se popularizaram e se disseminaram ainda mais após o surto. Representações do Juízo Final parecem se tornar mais populares, com uma ênfase cada vez maior nas figurações do Paraíso e, especialmente, do Inferno ${ }^{19}$. Mas não é apenas disso que trata Meiss e, especialmente, não é a isso que se referem estudos posteriores que tratam do "retrocesso" na arte pós-peste.

Alguns pontos precisam ser enfatizados nessa análise. Ao contrário do que Millard Meiss escreveu em seu livro, por exemplo, a representação da Virgem com o Menino continuou sendo o tema por excelência da arte cristã do fim da Idade Média ${ }^{20}$. Não há somente ênfase no milagroso, ou em temas sobrenaturais, pelo contrário. Meiss trata ainda desse retorno a uma arte mais espiritualizada, menos calcada na mímesis e, por conta disso, mais "primitiva", em uma conotação de todo diversa ao que Lionello Venturi havia dado a esse termo ${ }^{21}$. Entretanto, é fundamental que destaquemos que, se há uma quantidade expressiva de pinturas remetendo aos modelos tradicionais do passado, mais "arcaicos", seja do século XIII ou mesmo anteriores, isso não significa que não continue se desenvolvendo, de forma paralela, uma arte mais naturalista - conforme os ciclos executados por Taddeo Gaddi, com suas perspectivas, volumetrias e espacialidades, claramente mostram [Figura 3].

18 Esses temas estariam relacionados, na verdade, a uma cultura da penitência vinculada, por sua vez, a uma "tendência à vida ascético-eremítico-penitencial" que se desenvolvera na Europa na segunda metade do século XIII. Cf. Battaglia Ricci, 2000, p. 54.

19 Sobre o desenvolvimento das representações do Juízo Final no século XIV, ver Quírico, 2014. Cabe destacar que, mesmo nesse exemplo, as mudanças compositivas ocorreram antes de 1348 . Ainda sobre o desenvolvimento de novas temáticas na segunda metade do Trecento, devemos recordar que é nesse período que surgem representações de santos protegendo comunidades ou mesmo cidades inteiras da peste. Como escreve Judith Steinhoff, "esse tipo de imagem indica outra dimensão do clima psicológico, uma [dimensão] de esperança, que ajudou as pessoas a lidarem com medos durante o [surto] de 1348 e especialmente com os surtos sucessivos da pandemia ao menos até o século XVI". Steinhoff, 2020, p. 22. Estamos tratando, portanto, de um tema que traz esperança, e não desespero, a seus observadores. Para um estudo mais aprofundado a esse respeito, ver Marshall, 2002.

20 Ver acima, nota 10.

21 Ver nota 14 acima. 
Figura 3

Taddeo Gaddi

Lignum Vitae,

Última Ceia e

histórias sacras,

ca.1355-1360

Afresco, $1120 x$

$1170 \mathrm{~cm}$

Florença, Convento de Santa Croce,

refeitório

Disponível em: <https://commons.wikimedia. org/wiki/File:Taddeo_Gaddi_-_ Last_Supper, Tree_of_Life and Four Mira-

cle_Scenes_WGA08387.jpg>. Acesso em 24 de setembro de 2020

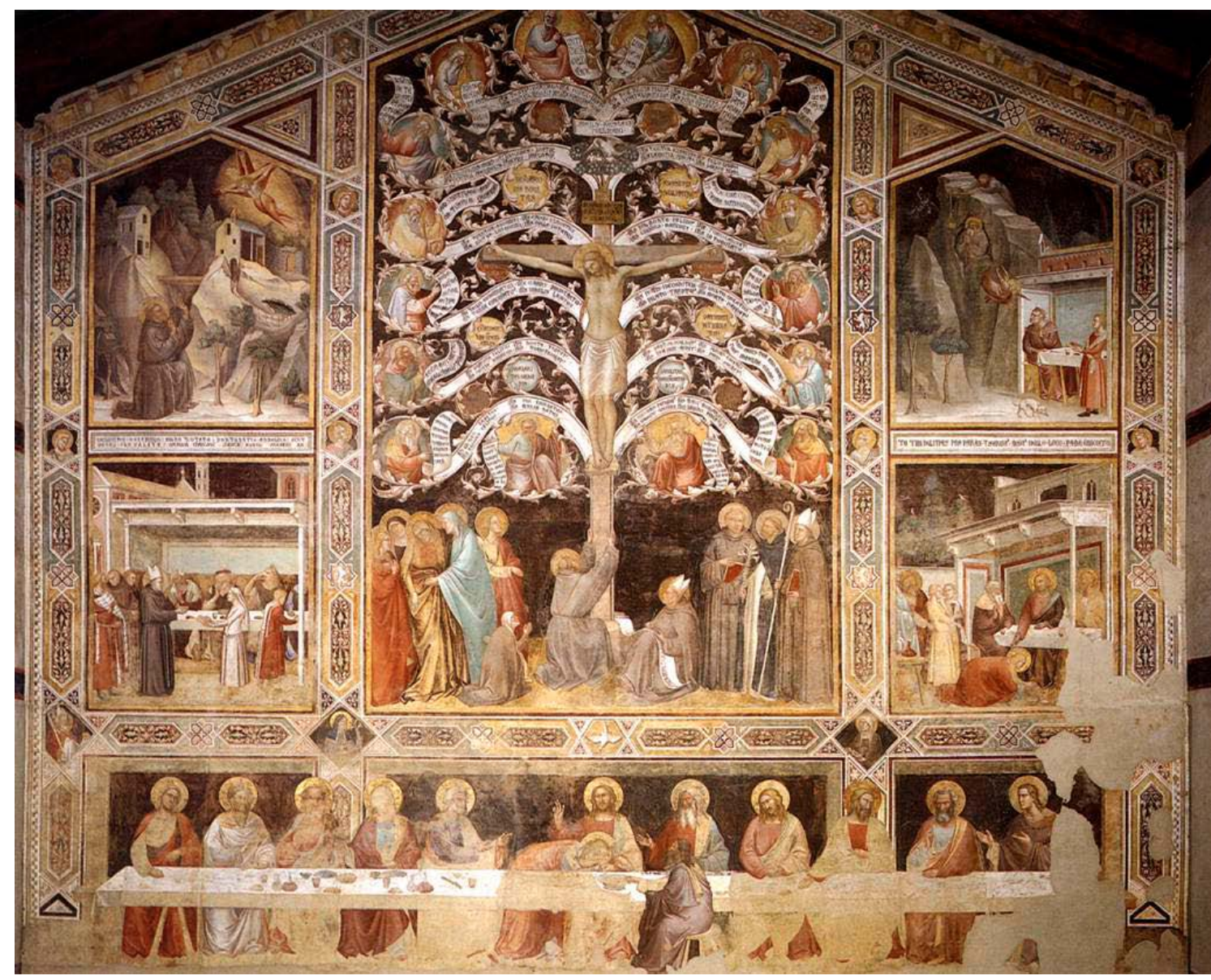

Ademais, o inverso é igualmente verdadeiro. Ou seja, as inovações trazidas à arte por Giotto na primeira metade do Trecento também não significaram, de modo algum, o abandono das tradições artísticas anteriores, que continuaram se desenvolvendo ainda na virada do século XV para o $\mathrm{XVI}$. Essa visão reducionista que trata não somente a História da Arte, mas a História de modo geral, em blocos estanques, enfatizando a ruptura, aquilo que é trazido de novo, portanto, e que ignora as continuidades e as complexidades que levam ao desenvolvimento de linguagens artísticas diversas de modo simultâneo, já deveria ter sido relegada ao esquecimento há muito.

Há, por fim, um elemento capital - talvez o mais importante - que tende a não ser considerado nessas análises mais superficiais sobre a produção artística desse período: a maior demanda por pinturas devocionais que percebemos nos últimos séculos da Idade Média, consequência do desenvolvimento de uma religiosidade católica baseada na estreita relação entre fiéis e imagens - e profundamente marcada por isso. Não abordaremos esse 
tema, já tratado em outra ocasião ${ }^{22}$. Recordemos, tão-somente, que, ao menos desde o início do século XIII (na Península Itálica, como observa Victor Schmidt, a produção de painéis pintados conhece um enorme desenvolvimento a partir da década de 1250) ${ }^{23}$, as imagens se tornaram, para o fiel cristão, as intermediárias privilegiadas entre o homem e o divino [Figura 4].

Figura 4 Berlinghiero Berlinghieri (atribu-

ído)

Tríptico com Virgem com Menino, Crucificação, Juízo

Final e santos, ca. 1230

Têmpera sobre madeira, 42,6 $\mathrm{x}$ $51,5 \mathrm{~cm}$ (medidas referentes ao conjunto de três painéis)

Cleveland, Museum of Art

Disponível em: <https://www. clevelandart.org/ art/1966.237>.

Acesso em 22 de setembro de 2020

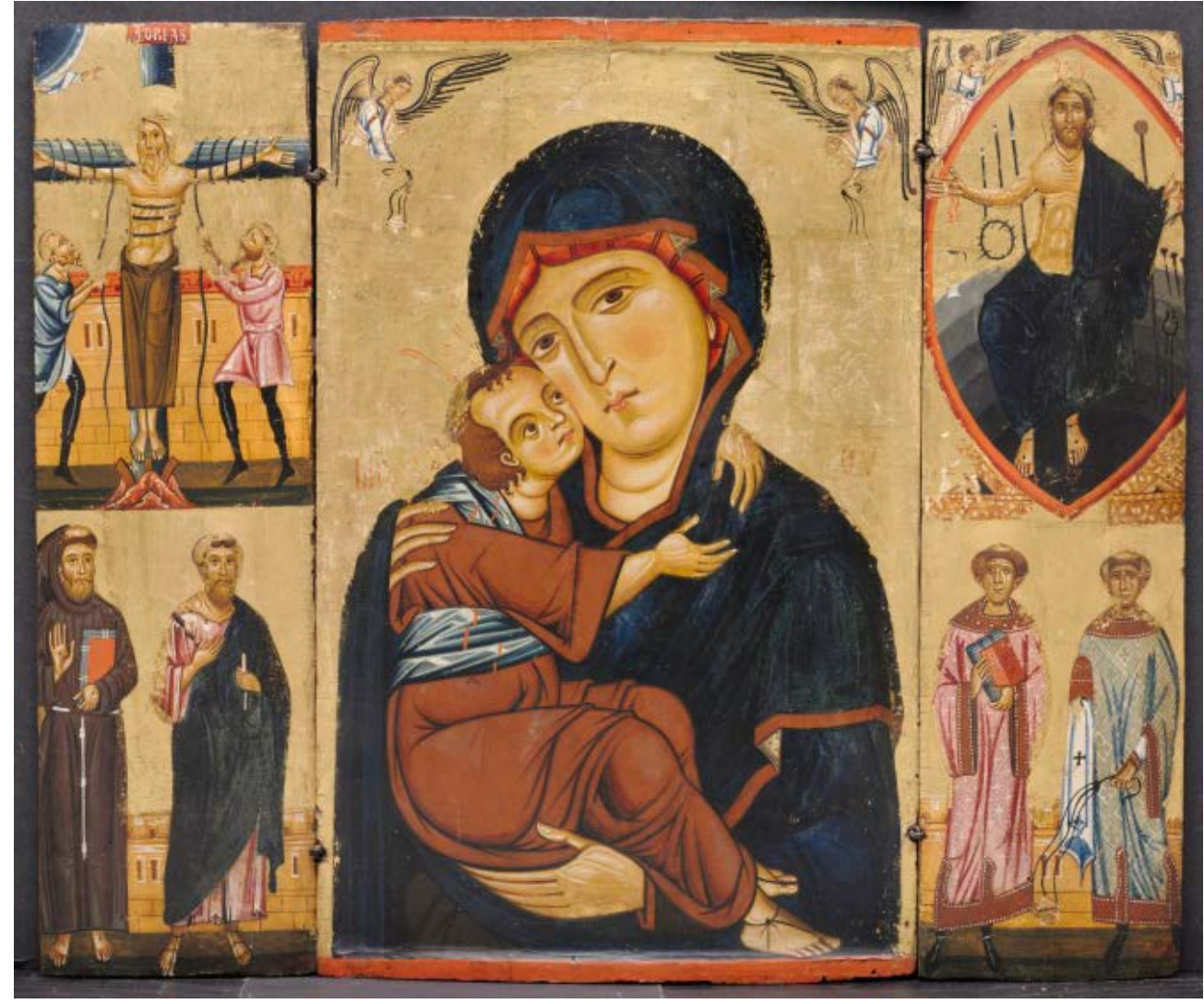

A essas imagens, assim, eram dirigidas preces pedindo intercessões diversas, inclusive, desde 1348, para que a peste fosse debelada [Figura 5]. É preciso considerar que, em momentos de crise ou angústia, os fiéis, não importa qual seja sua crença, tendem a buscar apoio no sobrenatural. Entre os católicos, frequentemente isso é realizado por meio de imagens, ainda hoje - uma das cenas mais impactantes relacionadas à atual pandemia foi, decerto, a visão de Papa Francisco em sua benção Urbi et Orbi re-

22 Quírico, 2015a.

23 Schmidt, 2005, p. 205. 
alizada no fim de março de 2020, quando, diante de uma Praça São Pedro vazia, e rogando pela intercessão divina para acabar com a epidemia de Covid-19, prostrou-se à frente do ícone milagroso conhecido como Salus Populi Romani (famoso por supostamente ter posto fim a um surto de peste em Roma no fim do século $\mathrm{VI}$, após ser levado em procissão pelas ruas da cidade pelo Papa Gregório Magno) [Figura 6].

Figura 5

Luca di Tommè

Trindade e Crucificação com cenas da vida de Cristo,

ca.1357-1360

Têmpera e ouro sobre madeira, $56,5 \times 53,4 \mathrm{~cm}$

San Diego,

Timken Museum of Art

Disponível em: <https://www. timkenmuseum. org/calendar/ event/spotlight-talk=29-/?backmonth>. Acesso em 02 de outubro de 2020

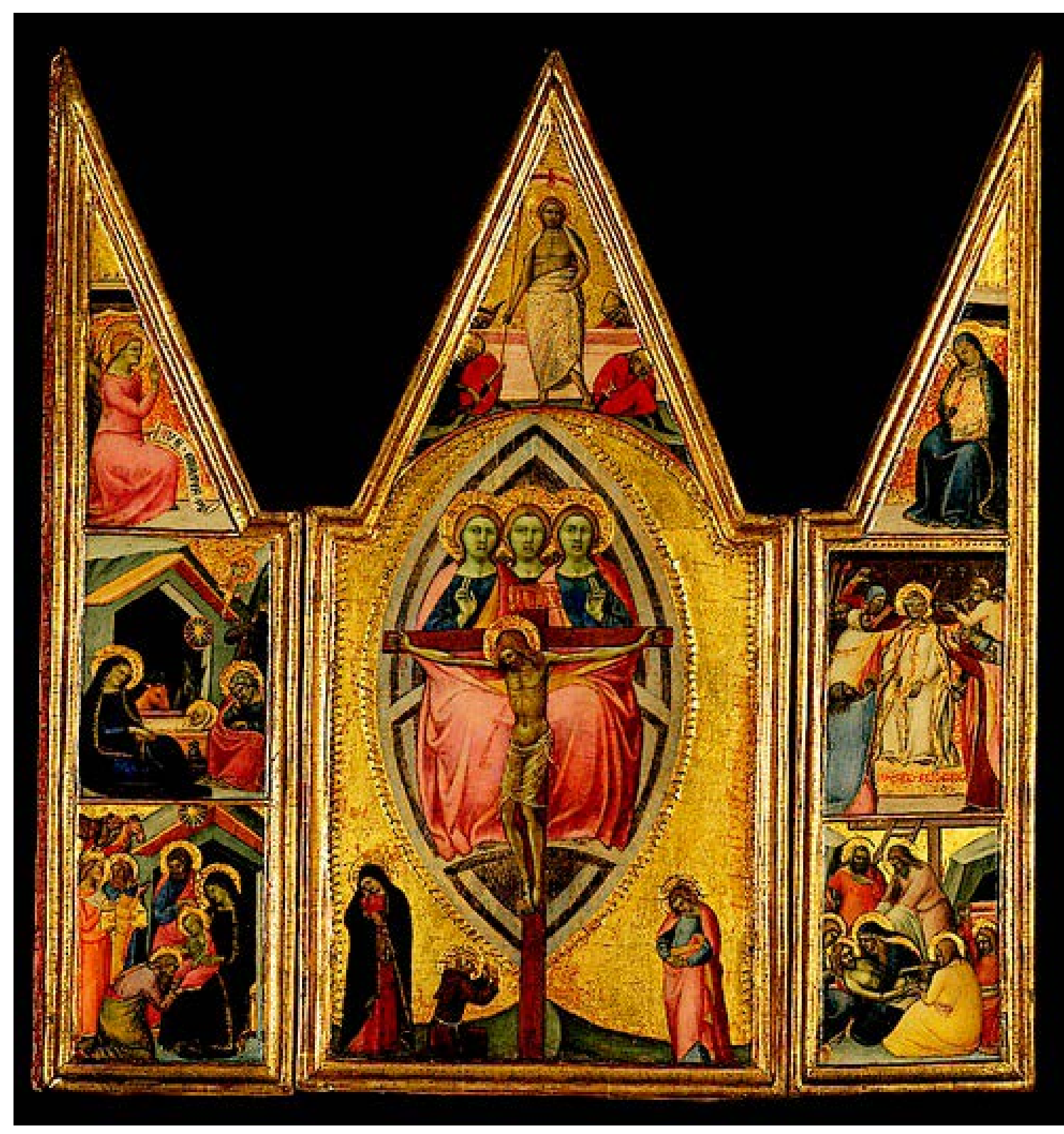


Figura 6

Papa Francisco

diante do ícone

Salus Populi Ro-

mani

Vatican News-

Disponível em:

$<$ https://www.

vaticannews.

$\mathrm{va} / \mathrm{pt} / \mathrm{papa} /$

news/2020-03/

papa-francisco-

-homilia-oracao-

-bencao-urbe-e-

t-orbi-27-marco.

html>. Acesso em

22 de setembro de 2020

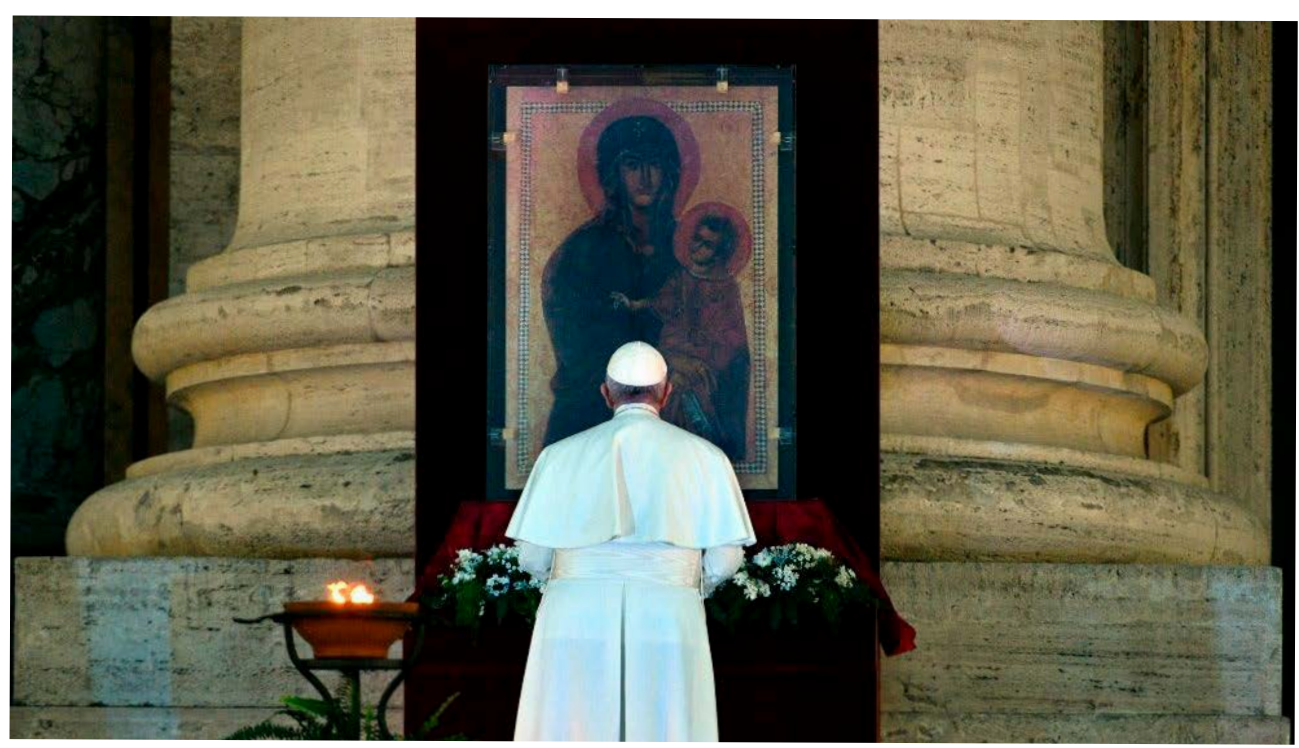

Essa nova religiosidade católica teve como consequência, desde meados do século XIII, o estímulo para o desenvolvimento de uma devoção pessoal. Esta era realizada, no mais das vezes, no interior das residências dos fiéis, e não mais nos edifícios religiosos, e em geral ocorria com o apoio de uma ou mais imagens - por isso definidas hoje como imagens de devoção -, que auxiliavam nos processos de meditação desses fiéis, e que vão se tornando, por essa razão, cada vez mais populares. As reduzidas dimensões do tríptico atribuído a Berlighiero Berlighieri (ca.1175-1235 ou 1236), atualmente no acervo do Cleveland Museum of Art [Figura 4], ou do tríptico de Luca di Tommè (ca.1330-1389) no Timken Museum [Figura 5], por exemplo, indicam claramente que ambos teriam sido encomendados para funcionarem como elementos portáteis de um altar doméstico, e não de uma igreja. Sua estrutura - três painéis independentes, ligados por dobradiças - permitiria o fácil manuseio desses objetos, que seriam mantidos abertos, exibindo as cenas principais, durante os momentos de oração, permanecendo fechados o resto do tempo. A distância de mais de cem anos entre a execução do tríptico de Berlinghieri e o de Tommè mostra como esse modelo de pintura, derivado diretamente dessa nova religiosidade, permaneceu fundamentalmente o mesmo. Painéis como esses, de fato, teriam existido em abundância na Europa, mostrando sua importância para esse catolicismo que se desenvolveu no fim da Idade Média e na Primeira Época Moderna. Nesse ponto, não houve mudanças que pudessem ser relacionadas à Peste Negra. 
Conforme comentamos previamente, uma das características mais evidentes dessas pinturas, mesmo na segunda metade do século XV ou já no $\mathrm{XVI}$, quando elas continuavam sendo fabricadas, é seu estilo mais convencional, mais afeito às tradições artísticas do século XIII e mesmo anteriores. Samuel Cohn e Judith Steinhoff argumentam que isso poderia ser explicado não somente pela expansão da requisição por esses objetos devocionais após a Peste Negra, mas especialmente devido ao fato de que essa demanda teria sido gerada, em grande medida, por novos grupos sociais que não podiam comprar objetos desse tipo no passado. Com as mudanças econômicas geradas pela peste, no entanto, eles passaram a ter condições financeiras para arcar com essa despesa ${ }^{24}$.

De fato, pouco se escreve sobre esse ponto: em termos econômicos, a população vivia, de modo geral, melhor após 1348; havia heranças a serem recebidas, e em muitos casos os herdeiros haviam diminuído de forma expressiva, como lemos em alguns registros de época: o cronista florentino Matteo Villani (1283-1363), por exemplo, escreveu em sua crônica sobre "homens se encontrando menos numerosos, e mais ricos por heranças e sucessões de bens terrenos", e que, como consequência da súbita riqueza, deram-se a uma vida de desregramentos ${ }^{25}$. Ademais, como comenta Steinhoff, "os legados testamentários dos mortos contribuíram para alguma redistribuição de riqueza e poder", tendo em vista que muitas instituições religiosas foram de certo modo beneficiadas através desses testamentos ${ }^{26}$.

Mas não estamos tratando somente de heranças - que pressuporiam condições sociais mais vantajosas. Mesmo entre as classes mais baixas, a

24 Cohn, Jr, 1992, p. 244 a 246, e Steinhoff, 2014, p. 05.

25 "Credettesi chelli uomini, i quali per grazia Idio avea riserbati in vita, avendo veduto lo sterminio di loro prossimi, e tutte le nazioni del mondo, udito il simigliante, che divenissono di migliore condizione, umili, vertudiosi, cattolici, guardassonsi dalle iniquità e da' peccati, e fossono pieni d'amore e di carità l'uno contra l'altro. Ma di presente, ristata la mortalità, aparve il contradio: che li uomini trovandosi pochi, e abondanti per l'eredità e successioni de' beni terreni, dimenticando le cose passate come state non fossono, si dierono a ppiù aconcia e disonesta vita che prima non avieno usata" ["Acreditava-se que os homens, os quais por Sua graça Deus havia preservado a vida, tendo visto o extermínio de seus próximos, e de todas as nações do mundo, ouvindo [coisa] semelhante, se tornariam melhores, humildes, virtuosos e católicos, evitando iniquidades e pecados, e estivessem cheios de amor e caridade um pelo outro. Mas no presente, cessada a mortalidade, aconteceu o contrário: que os homens se encontrando menos numerosos, e mais ricos por heranças e sucessões de bens terrenos, esquecendo as coisas passadas como se nunca tivessem existido, deram-se a uma vida mais vergonhosa e desonesta do que antes"]. Villani, 1995, p. 15 e 16.

26 Steinhoff, 2020, p. 21. Sobre a questão dos testamentos e seus legados, ver também Cohn, Jr, 1992, e Bacci, 2003. 
Peste Negra trouxe implicações econômicas positivas: sabemos, de fato, que os valores pagos aos camponeses e aos trabalhadores, de modo geral, também aumentaram, devido à diminuição da mão de obra especializada disponível ${ }^{27}$. Ou seja, retornando à questão fundamental que desejamos tratar aqui, na segunda metade do século XIV temos novos grupos sociais com condições financeiras de realizar encomendas de pinturas, algo antes reservado somente a uma elite econômica. Como nos recorda Cohn, "comissões para pinturas podiam ter origem em níveis mais baixos na escala social do que construções de capelas", decerto um empreendimento bem mais custoso ${ }^{28}$. E complementa que, ainda que poucas dentre essas obras tenham chegado aos dias atuais, sabemos, através de testamentos, que trabalhadores simples como açougueiros, sapateiros, padeiros, ferreiros, jardineiros ou verdureiros ${ }^{29}$ podiam pensar em se tornar patronos de pinturas sacras que seriam colocadas em edifícios públicos. Se tinham recursos financeiros para encomendar painéis ou afrescos para uma capela em uma igreja, por certo também podiam arcar a confecção de uma pequena pintura para sua devoção pessoal.

O aumento da demanda por esse tipo de pintura resultou em uma importante consequência: a maior organização e especialização dos ateliês, que precisaram alcançar um novo nível de profissionalização para que pudessem dar conta das encomendas. Essa maior especialização nos é conhecida em parte pela correspondência deixada pelo comerciante toscano Francesco di Marco Datini (ca.1335-1410). Sabemos, assim, da existência de uma estrutura extremamente organizada desses ateliês, em que havia obras "em estoque": pinturas representando a Virgem com o Menino, é claro, principal imagem de devoção entre os cristãos. Mas também painéis voltados para o culto a santos diversos, pintados previamente com figuras genéricas, e que seriam finalizadas em um segundo momento, quando uma encomenda determinaria qual santo deveria ser detalhado, com seus

27 Uma das consequências possíveis disso igualmente nos é apresentada por Steinhoff: "a reorganização socioeconômica também propiciou que algumas pessoas previamente pobres se tornassem donas de terras, conseguindo a propriedade que pertencera a indivíduos mais ricos, porém agora mortos". Steinhoff, 2020, p. 21.

28 Cohn, Jr, 1992, p. 245. Afirma Cohn que, se a construção de uma capela poderia custar em torno de 208 florins, a comissão de pinturas para decorá-la sairia por um valor até sete vezes menor (menos de 28 florins). Cf. Ibidem. Uma pequena pintura para devoção pessoal, por conseguinte, teria um custo bem inferior a isso.

29 Cf. Ibidem. 
respectivos atributos iconográficos ${ }^{30}$. Estamos falando, portanto, de uma produção em série de imagens que seguiriam um modelo-base, o que implica de antemão uma qualidade de todo diversa de pinturas exclusivas, realizadas a partir de uma encomenda específica de um comitente ${ }^{31}$. Qualidade diversa que, no entanto, não implica má qualidade, ponto que nunca parece suficientemente ressaltado na historiografia da arte desse período.

De fato, essas novas demandas trazidas por novos grupos sociais tocam em uma última questão capital para compreendermos as imagens cristãs de fins do Medievo. Quem desejasse encomendar pinturas devocionais, seja na primeira metade do Trecento ou após o surto de Peste Negra, ou mesmo já nos séculos XV ou XVI, usualmente solicitaria uma pintura que seguisse o modelo de alguma renomada imagem milagrosa - normalmente um modelo derivado de ícones bizantinos e, portanto, mais "arcaico" ou "primitivo". Como explica o historiador da arte Michele Bacci, esses novos painéis ecoariam a autoridade dos ícones antigos (ainda que alguns pudessem ter sido realizados muito mais recentemente, no século XIII), buscando reproduzir sua eficácia religiosa. Essas pinturas eram percebidas pelos fiéis como depositárias "de uma antiquíssima tradição que remonta à idade evangélica"32. Não podemos esquecer, nesse contexto, a persistência de uma crença segundo a qual São Lucas teria realizado uma pintura da Virgem com o Menino, que teria se tornado o modelo para representações posteriores - a própria imagem milagrosa da Salus Populi Romani, diante da qual Papa Francisco rezou, é tradicionalmente atribuída ao evangelista, embora saibamos que provavelmente se trate de uma pintura muito mais recente.

Além da Salus Populi Romani, havia diversos outros ícones milagrosos na Península Itálica nesse momento, e que ainda são considerados assim na contemporaneidade. Na região da Toscana, obras como a Madonna del Voto, pintada por Dietisalvi di Speme (ativo em Siena entre 1250 e 1291, quando morreu) nos anos 1260 [Figura 7], que permanece na capela de mesmo nome dentro da Catedral de Santa Maria Assunta, em Siena; ou ainda a chamada Madonna di sotto gli organi [Figura 8], atribuída ao mes-

30 Cf. Schmidt, 2005, p. 206.

31 E, como nos recorda uma vez mais Schmidt, "se painéis podiam ser fornecidos diretamente ou com poucas modificações a partir de um estoque, isso significa o pintor ter encomendado séries de painéis completos, com molduras, para o carpinteiro". Ibidem.

32 Bacci, 2009, p. 34. 
mo Berlinghiero Berlinghieri do tríptico de Cleveland. Esse painel passou a ser considerado uma imagem de devoção entre os pisanos desde 1225, quando foi levado para a catedral - onde ainda hoje se encontra - no contexto das lutas contra a cidade de Lucca, e adquiriu ainda maior importância no fim do século XV, quando a cidade, segundo a fé dos habitantes de Pisa foi libertada do domínio florentino por intercessão dessa imagem. $O$ exemplo da Madona di sotto gli organi é emblemático por evidenciar que, mesmo na virada para o Cinquecento, o modelo de religiosidade medieval, baseado na relação entre fiési e imagens, e no culto a ícones considerados milagrosos, ainda era predominante.

Figura 7

Dietisalvi di Spe-

me

Madonna del Voto ca.1260-1267

Têmpera e ouro sobre madeira,

$122 \times 82 \mathrm{~cm}$ Siena, Catedral de Santa Maria

Assunta

Disponível em: <https://commons.wikimedia. org/wiki/File:-

Dietisalvi_di_Speme Madonna.

jpg>. Acesso em 23 de setembro de 2020

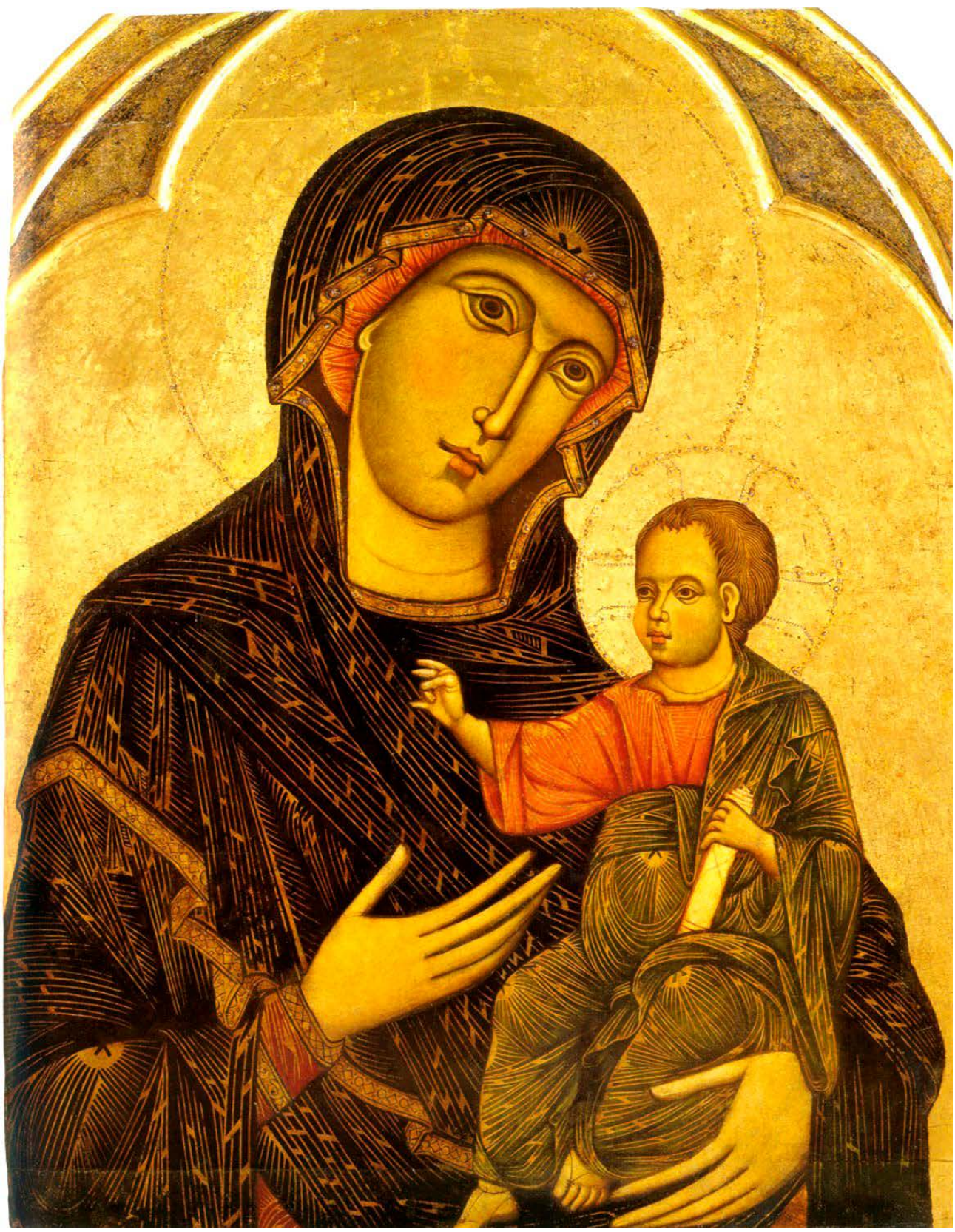


Figura 8

Berlinghiero Berlinghieri (atribu-

ído)

Madonna di sotto gli organi, ca.1200-1220

Têmpera e ouro sobre madeira, 93 $x 55 \mathrm{~cm}$

Pisa, Catedral de Santa Maria

Assunta.

Disponível em: <https://commons.wikimedia. org/wiki/File:Berlinghiero_o_pittore_bizantino._Madonna col Bambino._I_quatro del_XIII_secolo, Pisa,_Cattedrale.. jpg>. Acesso em 23 de setembro de 2020

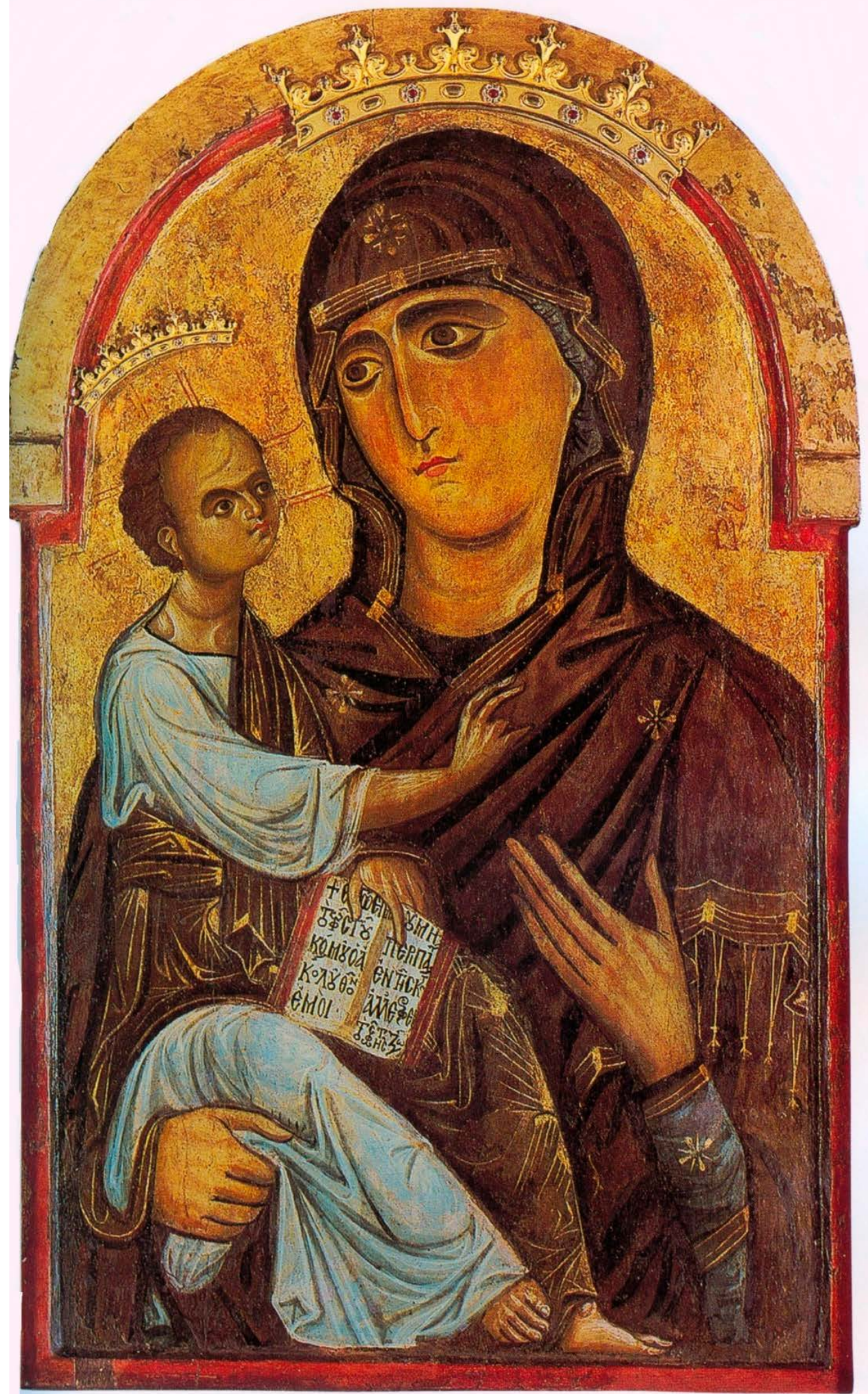


É esse, então, o modelo desejado e encomendado pelos fiéis, e não necessariamente uma pintura que atualmente muitos considerariam melhor, posto que calcada na mímesis. Essa preferência por padrões mais antigos, conforme discutimos, não significa um declínio da qualidade artística dessas imagens de devoção, apenas por não seguirem modelos naturalistas. Também não significa, de modo algum, que essas obras possam ser consideradas tecnicamente ruins, executadas por artistas de poucas habilidades que eram contratados pelos ateliês para que se conseguisse dar conta da grande demanda por essas imagens após o surto de Peste Negra, como já se desejou demonstrar ${ }^{33}$. Seu estilo não é o resultado de falta de qualidade técnica, mas de uma opção consciente dos comitentes, e seguida pelos pintores. Não podemos hoje, portanto, continuar perpetuando informações ultrapassadas e preconceituosas sobre a arte pós-1348, pois não se trata, em absoluto, de retrocesso. Trata-se, isto sim, da ênfase em uma religiosidade católica cuja devoção popular se sustentava, em grande parte, nas imagens elaboradas a partir de modelos antigos.

\section{Bibliografia}

BACCI, Michele. "Immagini sacre e pietà 'topografica' presso i Minori”. In: Le immagini del Francescanesimo. Atti del XXXVI Convegno Internazionale. Spoleto: Centro Italiano di Studi sull'Alto Medioevo, 2009 . Investimenti per l'aldilà. Bari: Laterza, 2003

BASTOS, Mário Jorge da Motta. O poder nos tempos da Peste (Portugal séculos XIV/XVI). Niterói: EdUFF, 2009 
BATTAGLIA RICCI, L. Ragionare nel giardino: Boccacio e i cicli pittorici del Trionfo della morte, $2^{\mathrm{a}}$ edição. Roma: Salerno, 2000 [1987]

BOWSKY, William M. "The impact of the Black Death upon Sienese government and society". In: Speculum, volume 39, n 1, janeiro 1964

BURCKHARDT, Jacob. A cultura do Renascimento na Itália. Um ensaio (trad. S. Tellaroli). São Paulo: Companhia das Letras, 2009 [1860]

COHN, Jr, Samuel K. The Black Death transformed. Disease and culture in Early Renaissance Europe. Nova York: Oxford University, 2002

. The cult of remembrance and the Black Death. Six Renaissance cities in Central Italy. Baltimore: John Hopkins University, 1992

FIUMI, Enrico. Storia economica e sociale di S. Gimignano. Florença: Olschki, 1961

GOODICH, Michael. Violence and the miracle in the fourteenth century. Private grief and public salvation. Chicago e Londres: Chicago University, 1995

KNIGHT, Christopher. "Bubonic plague in Europe changed art history. Why coronavirus could do the same". In: Los Angeles Times, 29 de março de 2020. Disponível em: <https://www.latimes.com/entertainment-arts/ story/2020-03-29/coronavirus-bubonic-plague-millard-meiss-black-death>. Acesso em 15 de abril de 2020

LE GOFF, Jacques. Em busca da Idade Média (trad. M. de Castro). Rio de Janeiro: Civilização Brasileira, 2008

LERNER, Richard E. "Antichrists and Antichrist in Joachim of Fiore". In: Speculum, volume 60, n³, 1985

LORENZI, Lorenzo. "La pittura di morte a Firenze al tempo dei terribili fatti del 1348". In: Città di vita, 51, n² 2, 1996

MARSHALL, Louise. "Reading the body of a plague saint. Narrative altarpieces and devotional images of St. Sebastian in Renaissance art". In: MUIR, Bernard J. (org.) Reading Texts and Images. Essays on Medieval and Renaissance art and patronage. Exeter: University of Exeter, 2002 
MEISS, Millard. Painting in Florence and Siena after the Black Death. Princeton: Princeton University, 1978 [1951]

QUÍRICO, Tamara. "Renascimento ou longa Idade Média? Considerações sobre a arte italiana entre os séculos XIII e XV". In: LANZIERI Jr, Carlile (org.). As faces da Renovatio na Idade Média e no Renascimento. Cuiabá: Vivarium, 2018

. "Apontamentos para um estudo dos séculos XIV e XV como momento de continuidade". In: RAGAZZI, Alexandre, MENESES, Patricia D. e QUÍRICO, Tamara (org.). Ensaios interdisciplinares sobre o Renascimento Italiano. São Paulo: Unifesp, 2017

"Devoção por imagens: pinturas e culto privado na Itália entre os séculos XIII e XV". In: Figura. Studies on the Classical Tradition, volume 3, $2015 a$

- "Sobre datação e atribuição de obras de arte: o caso do ciclo do Trionfo della Morte no Camposanto de Pisa". In: Diálogos Mediterrânicos, volume $8,2015 b$

- Inferno e Paradiso. As representações do Juízo Final na pintura toscana do século XIV. Campinas: Unicamp, 2014

"A representação do Cristo Juiz em pinturas toscanas do Trecento ao Cinquecento". In: Concinnitas, volume 2, 2013

- "Peste Negra e escatologia: os efeitos da expectativa da morte sobre a religiosidade do século XIV". In: Mirabilia, volume 14, 2012

SARDO, Ranieri. Cronica di Pisa (org. Ottavio Banti). Fonti per la storia d'Italia, n. ${ }^{\circ}$ 99. Roma: Istituto Storico Italiano per il Medioevo, 1963 [1399]

SCHMIDT, Victor M. Painted piety. Panel paintings for personal devotion in Tuscany 1250-1400. Florença: Centro Di, 2005

STEINHOFF, Judith. "Thoughts on Medieval art and two pandemics". In: ICMA Newsletter, Summer 2020, n. ${ }^{\circ} 2$

Sienese painting after the Black Death. Artistic pluralism, politics and the new art market. Cambridge e Nova York: Cambridge University, 2014 
VENTURI, Lionello. Il gusto dei primitivi. Turim: Einaudi, 1972 [1926]

VILLANI, Matteo. Cronica. Con la continuazione di Filippo Villani, 2 volumes (org. Giuseppe Porta). Parma: Fondazione Pietro Bembo/Ugo Guanda, 1995 [1364]

WOLFF, Philippe. Outono da Idade Média ou Primavera dos tempos modernos? (trad. C. Sarteschi). São Paulo: Martins Fontes, 1988. 